\title{
Student motivations for undertaking a child and adolescent psychotherapeutic counselling course
}

\section{Carol Holliday, Fiona Peacock \& Clair Lewoski}

Carol Holliday is a UKCP registered arts psychotherapist, an educator and researcher. She is an affiliated lecturer at the faculty of Education, University of Cambridge and her special interests are in developing professional knowledge and working with the arts in therapy, education and research.

cah66@cam.ac.uk

Fiona Peacock is a BACP Senior Accredited Counsellor/Psychotherapist and Certified Theraplay® Therapist, Trainer and Supervisor. She is a Teaching Associate at Faculty of Education, University of Cambridge as well as running a private practice providing highly specialist interventions for Children who are Looked After or Adopted. She is studying for an Ed.D.

fmp31@cam.ac.uk

Clair Lewoski is a UKCP Reg. Child Psychotherapist and HCPC Reg. Dramatherapist. She teaches on the Child and Adolescent Psychotherapeutic Counselling Training at Cambridge University, where she is also studying for her doctorate and works in private practice seeing children, families and supervisees.

c1572@cam.ac.uk

\begin{abstract}
Tutors of a child and adolescent psychotherapeutic counselling programme undertook a thematic analysis of five student assignments, from the same student cohort, designed to investigate their motives for undertaking the course. The assignments were thematically analysed utilising ideas derived from consensual qualitative research and narrative inquiry. The stories suggest that students identify relational adversity in childhood or adolescence, manifestation of emotional distress, restorative experience of relationship and being available for relationship as being key factors in their motivations to become therapists. Additionally there were both commonalities and differences when compared to existing literature concerning motivations of therapists who do not intend to work with children with children. These findings have implications for therapists, supervisors, educators and accreditors of counsellors and psychotherapists.
\end{abstract}

\section{Background}

This project stems from the experiences of tutors teaching on a child and adolescent psychotherapeutic counselling programme at a Faculty of Education in a British university. The programme runs over four years and students progress through Postgraduate Diploma 
and Masters awards to gain a qualification to be a practitioner who works therapeutically with children and young people. It is nationally accredited as a practitioner education and thus marries professional requirements with the demands of a research degree. The theoretical stance of the programme is integrative, ecosystemic, developmental and relational; there is a strong emphasis on working with the arts and play throughout the programme. Theory and its application to practice and personal development are key elements throughout the programme and are part of a formative and ongoing assessment process. Formative assessment is integrated with summative assessments of students' progress through academic assignments, closely observed video practice, case presentations, and viva voce. The programme is highly experiential and seeks to develop practitioners' practical wisdom or phronesis (Holliday, 2015) through reflection on learning experiences.

The first assignment of the programme is a written task where students are invited to reflect on their personal and professional learning. They are required to articulate their learning from the formative experiences that have propelled them to come to this course to learn to be therapists who intend to work with children and young people. It is to be noted that this assignment is undertaken in the first term of the course so students are writing without a depth of understanding of counselling or psychotherapy theory. The aim of this assignment is to lay the foundation for the work they will undertake on the programme. This is predicated on the belief that the person of the therapist is the instrument of the therapeutic work and that the person of the researcher is the instrument of qualitative research. Students are asked to demonstrate their self-awareness, and show their understanding of their values and beliefs and to reflect on where these come from. They are encouraged to find and articulate 'the engine that drives them'. The raw data for this assignment is the life story of the student and in order to begin the task they spend some class time in small groups to recount their stories to fellow students whose task is to respond in an accepting, genuine and empathic manner and to help tease out meanings from the experiences. The following questions are offered to them as prompts:

What are your strengths?

What are your weaknesses?

What is most important to you?

What have you discovered?

What knowledge/skills/personal qualities have you developed?

What are you proud of?

What are you excited about?

What are your achievements/ accomplishments?

What are the critical incidents, the turning points?

Is there a common thread?

In order to support them further in their writing they are directed to part one of McLeod's (2011) workbook, which aims to facilitate self-awareness and self-understanding. We also draw the attention of students to the issues involved in writing about personal material in work that will be assessed. We discuss with them the challenges and struggles of being authentic in this context. We strive to develop a strong working alliance with our students to 
facilitate psychological safety and trust throughout the course. Students are all in personal therapy for the duration of the course and this contributes to their psychological safety.

The impetus for including this assignment in the programme came from Carol Holliday's experience of undertaking a professional doctorate in psychotherapy at the Metanoia Institute where a review of personal and professional learning was integral to the programme. Maja O'Brien (2015) who led the module discusses its significance, in terms of becoming a researcher, as linking the past with the future. The Metanoia programme, in turn, originates from the professional doctorate at Middlesex University that begins with a review of previous learning, which illuminates personal and professional development to date (Doncaster and Lester, 2002).

Seven cohorts of students on this course have now engaged in this assignment. We, the tutor team, found the accounts of the student's motivations to be fascinating, moving and illuminating. There seemed to be commonalities and this project seeks to formally identify these by undertaking a thematic analysis to answer the questions:

What do these essays tell us about what students identify as their motivations to study to become psychotherapeutic counsellors?

Why have they chosen to specifically study to work with children and young people as psychotherapeutic counsellors?

How do the tutors understand these motivations?

The purpose of this paper therefore, is to address the under-researched question of what motivates people to train as child and adolescent counsellors.

\section{Literature review}

In the UK there are a growing number of counsellors practising with children and young people. Current evidence suggests between 70,000 and 90,000 young people are seen in secondary schools alone (Cooper, 2013) and the Department for Education has recently stated that 'Our strong expectation over time is that all schools should make counselling services available to their pupils' (DfE, 2016b, 11). The demand for child and adolescent counselling trainings has grown exponentially over the past decade, to which the recent uptake of the MindEd Counselling training programme attests to with 13,970 learners accessing this webbased resource in the first few months since its launch (Therapy Today, 2014) An understanding of what draws people to the profession, their motivations in particular, remains under-researched however, as demonstrated by the paucity of literature available. A review of the literature elicited no research studies as to why people choose specifically to train as child and adolescent counsellors; nor as child psychotherapists or child psychologists. However, there is a single study by Guttman and Daniels (2001),involving 74 Israeli high school counsellors (in Tel Aviv)which considers the gains or benefits they received as part of their 
role and thus the implications for their motivation for choosing the profession. They identify 'narcissistic gains', such as increased self-worth, self-confidence and self-validation as the primary motivators, for choosing the profession, alongside less conscious narcissistic or need fulfilment gains, such as a sense of power and control and a fulfilment of dependency and intimacy needs. The application of this study to our current research is somewhat limited, as its research subjects were experienced counsellors, rather than trainees freshly in touch with their current motivations and additionally were all female). The idea that counsellors may choose the profession based upon narcissistic needs is supported in the literature. Barnett (2007) has explored in depth, adult motivations to train as therapists through interviewing nine experienced psychoanalytic psychodynamic psychotherapists about their professional and personal histories

Although there is sparse literature relating to motivations to train as adult counsellors or therapists, one theme which does emerge from the existing literature, is how personal experiences, particularly those occurring in childhood, appear to influence the choice to train as a therapist (Barnett, 2007; DiCaccavo, 2002; Burton and Topham, 1997 and Fussell and Bonney, 1990). Fussell and Bonney, whose study compared the childhood experiences of psychotherapists and physicists, found psychotherapists reported significantly more parental absence in childhood due to death, prolonged illness, separation or divorce. Early childhood experiences of loss, were also identified as a motivation to train as a therapist by Barnett (2007, p. 259) and DiCaccavo (2002, p. 469). Burton et. al. link the early loss of parental care in particular, to a motivation to train in the helping professions and particularly in psychotherapy. Early loss of parental care is seen in the literature as providing the conditions, which can lead to 'parentified children' who then go on to seek a 'professional care-giving role,' in the form of becoming a counsellor/therapist (Burton et. al; Barnett; DiCaccavo). Burton et. al define a 'parentified child' as a child in the caretaking role of their parent (1997, p.278). The term, 'parentification' has emerged from psychoanalytic literature and object relations theory and is defined as 'the subjective distortion of a relationship as if one's own partner or even child were his parent' (DiCaccavo, p.464). All 3 authors argue that this inversion of the parental role, with the child becoming the caretaker of their parent, is a motivator to train as a therapist, as the role is familiar and may bring some vicarious caring for oneself at a distance (DiCaccavo, p.464). However, research by Murphy and Halgin (1995) questions whether this and/or a troubled family history, are primary motivators for only a small proportion of people wishing to train as therapists. Instead, they argue a more significant motivator emerging from their research is a previous strong interpersonal alliance, such as with a therapist or familial figure as a role model, or being a confidant oneself during one's youth (1995, p.425). The relevance of being a confidant in one's youth in the desire to train as a therapist, is also supported by Barnett (2007, p. 264), although it is linked to an extension of the need to care for others. Murphy and Halgin therefore challenge the idea of the 'wounded healer', as being a significant motivator, which conflicts with the rest of the literature cited (Barnett, 2007; DiCaccavo, 2002; Burton and Topham, 1997 and Fussell and 
Bonney, 1990). However, the participants in the Murphy and Halgin project are clinical psychologists working as psychotherapists rather than those who have clearly opted for a counselling or psychotherapy course and this might account for the differences found.

In summary, the current literature, although sparse, indicates that motivations to train as therapists are varied. Common motivators identified in most of the studies are the seeking to meet narcissistic, dependency and intimacy needs, the professionalization of a childhood role of caretaking others and seeking to emulate a role model.

Given the present governments' increasing focus upon the mental health and well-being of children and young people (DfE, 2015a; DfE, 2015b; DfE, 2016a; DfE, 2016b), we might concur with Barnett's assertion that given the growing 'public demand for therapeutic help', it is perhaps both, 'timely and crucial', to give not only more careful consideration to the selection and training of those wishing to work in this field, but also to the underlying motivations for making that choice in the first place,' (p.258). This is even more important when it comes to the selection and training of those who wish to work with vulnerable children and young people. With the potential increase in demand for people to work therapeutically with vulnerable children and young people this is a pertinent issue to explore in order to assist with safeguarding.

\section{Research approach and method}

In terms of philosophical stance, we are taking a constructivist approach (Ponterotto, 2005). We commit to being highly reflective and reflexive throughout. Reflection involves looking back and thinking about what happened. Reflexivity is on the spot reflection or reflection in action. This means we thought about the impact we had and are having on the project. We, the authors of this paper undertook the analysis on the essays and we are also the teaching team on the course. We strive to be transparent in our thinking and expectations of the project so that readers can judge the trustworthiness of our arguments. We have made explicit the theoretical framework on which this project is predicated. At the same time, as in Consensual Qualitative Research (CQR) (Hill, 2005) and Narrative Inquiry (NI) (Clandinin, 2007), we are privileging the voices of the participants and we are mindful of the value of narrative knowing and honouring the voice of the storyteller (Etherington, 2004). Our work both pulls apart to illustrate themes and weaves together to create new knowledge. We draw on CQR in that we are collecting consistent data and employing several judges, in this case the authors of the paper, to foster multiple perspectives and coming to a consensus of what is included (Hill, 2005). We believe there to be the possibility of a richer picture and more robust findings from working consensually in this context.

Ethical considerations are significant when researching with students and there are potential tensions in such dual relationships. To mitigate these we did not undertake any analyses of the essays until the students had completed all the assessed pieces of work for their degrees. We 
explained the project before the end of the course and then subsequently invited participation by email. Participants, therefore, had to opt-in by sending us their essays for inclusion. Five out of ten in the participating cohort did so. Our decision to invite participants to opt-in prizes the ethical principle of autonomy. The risk of this decision is that fewer essays would be submitted. The alternative of opt-out was considered but our decision was to prize autonomy. The essays were anonymised and names were changed. For some of the students their experience of religion was important to them. In order to keep the responses anonymous specific religions have not been named but the comments generalised. The essays were 4000 words long. All were written to the same open brief described above. This allowed material to emerge that had not been specified in advance and each participant could write about what was most meaningful to him or her.

\section{Analysis}

Individually, we read the essays line-by-line, and highlighted phrases that described emotional experiences. We looked for frequency and emotional intensity whilst acknowledging that we perceive these through our own individual lenses; forged from our personal and professional experiences and theoretical orientations. We also acknowledge that frequency does not necessarily mean that participants held it in more importance. For each essay we identified, separately, what we thought and felt were the key themes. We then met to compare findings and reach a consensual agreement of main themes across the whole data set. This consensus was easily reached, perhaps because as tutors on the same course we are already a community of practice and have shared perspectives. We came to the meeting with the same identified findings but initially with slightly different language, this was resolved through discussion and we agreed a form of words. For example, all of us identified relationship to be key but one author had framed the theme as 'loss of relationship'. The discussion involved finding a form of words that captured the whole of the theme and the differently nuanced understandings. This led to agreement on the term 'relational adversity'. There is of course the possibility that our shared perspectives preclude us from seeing an alternative view. On the other hand we each have a different emphasis in our understandings of counselling and psychotherapy as we each have different backgrounds in that our initial trainings were different.

Themes and evidence

In the analysis of the essays and through discussion and dialogue between the researchers the following themes were found to be present in the majority of the essays and the frequency of themes is shown below in figure 1 .

- Relational Adversity in Childhood or Adolescence

- Manifestation of Distress 
- Restorative experience of relationship

- Being available for relationship

[Figure 1. Here]

Figure 1. Frequency of themes

Relational adversity in Childhood or Adolescence

Each of the 5 research participants identified issues that appeared to indicate their relationships with others were difficult in a way that impacted on their sense of themselves. These 'relational adversities' clustered around several themes as follows:

1. Conflict between parents.

Emily wrote

"Both my parents had problems with alcohol and there would be frequent arguments, which would occasionally result in violence” (Emily page 1)

Such arguments, although classified here as 'conflict between parents' could equally be seen as parents inability to be available to Emily and alcohol use could well have been a mask for undiagnosed mental health difficulties. However, in classifying the relational adversity the research participants' perspective has been privileged.

“My parents' relationship began to deteriorate and frustration and anger started to replace the previously happy atmosphere. When I was five my father left home and returned a year later. My mother struggled to cope on her own and although she was pleased he had returned, life was never the same again. "(Cathy page 2)

2. Conflict with mothers, we notice the examples given all relate to mother and surmise that in these cases mother is likely to be the primary care giver.

"I could for example offer an explanation for the continual conflict with my mother between the ages of fourteen and sixteen" (Ben page 1)

"I went to University ... The anger at my mother had subsided, although I continued to have a difficult relationship with her" (Emily page 3) 
"When I was a young teenager I began to have a difficult relationship with my mum. I'm not completely sure at what age it started but I vividly remember this in my $14^{\text {th }}$ and $15^{\text {th }}$ year" (Alice page 5)

3. Bullying

"I have uncomfortable memories of being bullied for such irrational reasons as the clothes I wore, my religious beliefs and my father's profession and the accompanying feelings of isolation and loneliness. Even friendships were a far cry from my childhood experiences with acceptance, congruence or understanding replaced by judgement, falseness and derision” (Ben page 3)

4. Loss of parental availability and parents struggling with mental health issues "As the child of a religious and community leader, I often felt that I was less important than the people in my father's congregation. I rarely saw my father during the week as he left the house before I woke up and returned after I was already asleep and although he made great efforts to spend quality time with us children over weekends, the message that the people in the community came first was unconsciously drilled into me."(Debbie page 3)

5. Invalidation of a sense of self "My journey from childhood to adolescence and most recently early adulthood is marked by the struggle for individual identity against societal and family pressures and has shown me that any idea of my 'self' as a coherent, unified whole is not consistent with experience." (Ben page 1)

"I also had the burning desire to be special and at the heart of heart was a yearning to be valued and loved." (Emily page 3)

"The transition from childhood into adolescence brought about such conflict, in this case between internalised parental values and authority and new external forces from peers and the world around me ..............Much of my teenage life was spent choosing whether to accept my childhood self and its values or reject these and experiment with an alternative way of being. In reality I chose to discard portions of my childhood self to win the acceptance of others" (Ben page 1)

From my earliest memories, I recall feeling inferior to my big sister. I viewed her as a golden child, as someone who could do no wrong in my parents, and particularly my mother's, eyes. She was bigger, stronger, more confident and more able then I was. (Debbie page 1)

Relational adversity, particularly in early childhood was discussed in several of the papers cited in the literature review and these findings support these claims. 


\section{Manifestation of Distress}

These experiences of relational adversity seemed to lead to distress being manifested. Many of the descriptions used by the research participants could be seen as mental health difficulties even where these hadn't been formally diagnosed or where the research participants didn't name the manifestation of the distress as a mental health issue. The distress was also presented as experiences of isolation, shame or loneliness.

1) Mental Health Issues

"The loss and separation from close friends and parents that I experienced through the primary years culminated in the onset of a serious eating disorder. "(Cathy page 4)

"As a child I didn't have control of my bladder" (Debbie page 3, no diagnosis or recognition of enuresis)

"I withdrew into myself and switched from being an outgoing, mostly happy person with lots of friends to a withdrawn, sad, scared and lonely individual. I was depressed, but did not know it at the time." (Debbie page 7)

"It was the only way I could release the unbearable pain inside. My situation continued to worsen which led to more intense emotional turmoil, which in turn led to more severe methods of self-harm. I started cutting with a knife, which scared me so much; it led me to realise that I needed help" (Debbie page 6)

"Out of school my acting out took the form of self-harming and drinking” (Emily page 2, Emily went on to talk about drug use)

"Even friendships were a far cry from my childhood experiences with acceptance, congruence or understanding replaced by judgement, falseness and derision. Personal therapy has highlighted how much these experiences still impact me today and that it will be a battle to regain the congruence of childhood over the external locus of evaluation and need to be accepted developed as a teenager. "(Ben page 3)

2) Isolation, Loneliness and Shame

"Losing these close friends at a time of transition and change in both my school and family life, had a deeply disturbing effect on me. My resilience and sense of wellbeing seemed to vanish overnight." (Cathy page 2)

"With this [enuresis] came immense feelings of shame. I was teased mercilessly at school when the other children found out that I was a bed wetter. I felt insecure, 
unconfident and inferior to my peers, as they all managed to successfully control their bodily functions. "(Debbie page 3)

"Besides my acting out were the uncomfortable emotions I was struggling to cope with, such as a strong feeling of being shamefully different" (Emily page 3)

"Single. Lonely. Worried. Known yet unknown. A stranger to myself. Male. Excited. Complex. Scared of the future. Fearful of a life that fails to transcend the ordinary. Unsure if I have the capacity to be different. Intimidated by the choices I have made. Self loathing. Confident. Hopeful. Impatient. Despairing. Sad. Lonely. Craving intimacy. Frustrated by my own inadequacy. Searching for truth." (Ben page 2)

"The experience of my teenage years is in such contrast to my early childhood insecurity, loneliness, self-consciousness, awkwardness and fear - and yet through reflection and reconsideration they have become just as powerful in my motivation for becoming a counsellor" (Ben page 3)

Restorative experiences of relationship

All the research participants talk about positive experiences of relationships that were significant in leading them to the choice to train as a child and adolescent counsellor. For the majority of the participants these restorative relationships were traced back to an individual. Sometimes, in addition to that individual relationship, the group context of the individual was important. However, for one participant it was finding a restorative relationship in a learning setting that was most significant.

"I decided to sign up for the volunteer training. The experience changed my entire view about counselling. I was learning active listening skills, I was experiencing empathy, congruence ( a complete genuineness) and unconditional positive regard (prizing of the self as a human being) (Rogers, 1951) as it was intended to be experienced and I realised how much was missing from my first encounter with counselling." (Debbie page 7)

"Corporate identity and engaging in team games can give a real sense of belonging and of fair play and, as in the case described by Meredith Owen (2007), may compensate for the loss of the familiar environment.' (p.149-150). This was my experience. I quickly made new friends and had consistent care from two dedicated housemistresses, over the four years I was a student. "(Cathy page 6 talking of her experiences of boarding school to address her eating disorder).

"As I became part of a caring, religious community, I began to recover emotionally. We became friends with one family in particular and through them, I was able to observe a 
'normal' marriage relationship and 'normal' relationships between parents and their children." (Cathy page 6)

"I met a decent and straightforward guy and, although miles from my usual type, I decided to fight for him. This involved me in dealing with things such as my drug taking...Looking back now I believe that the combination of theses crises and having something to fight for inspired me to tackle my panic attacks once and for all, which led me to three years of counselling. Later on this experience was to fire my own interest in becoming a counsellor. (Emily page 4)

"Some of my strongest memories include community events such as fêtes, sports days, family lunches, school trips and religious meetings. Consciously or not, I had begun to understand the importance of 'togetherness', of shared experience and inclusion that transcended family, whether sitting round the dinner table to eat or congregating to worship God. I still feel a strong association between happiness, contentment and freedom and relationship, family and community that clearly originates from this period. It is perhaps no surprise then that I have selected a career which seeks wholeness in relationships and individuals." (Ben page 3)

"It was around my $15^{\text {th }}$ year when I joined a local youth club. At first I just joined as all my peers were joining, but soon I was to meet the lady who I build such a relationship with, she helped me to make better decisions." (Alice page 5)

This theme of experiencing restorative relationships resonates with findings from the literature, cited earlier, where seeking to emulate a role model was found to be a motivation.

Being available for relationship

The fourth key finding that emerged in our analysis of the material was harder to define and eventually several facets of the participants narratives led us to feel there was a theme of their availability for and desire to create healthy relationships with others, particularly children and young people, that propelled them towards a choice of training as a child and adolescent counsellor. This availability for relationship was presented in a variety of forms, which were distilled into the following areas:

- Faith

For Debbie, Ben and Cathy their experiences in faith communities impacted on their desire to be available for relationship. The impact could be framed in a positive way or in a less than positive way.

"As a child of a religious and community leader, I often felt that I was less important than the people in my fathers congregation” (Debbie page 3) 
"Therefore, despite growing up in a home with loving parents who endeavoured to meet my every physical, spiritual and emotional need, I came away from my childhood with a prevailing sense of being worth less than those around me." (Debbie page 4)

"However, the most important discovery that I have made in this personal and professional review is the importance of the relationship." (Debbie page 10)

"This had already begun at boarding school and now continued in the wider religious community and at my new school. Just as I learned that rebuilding trust in broken relationships is a small step daily process, so I learned that I needed others to help me along the way. It is interesting for me to reflect on the fact that I have been involved in building what Perry (2006) terms, 'healing communities' (pg.231) my entire adult life. Being in a religious community which fosters a strong sense of belonging, centred around a common faith, has brought healing, not only to me, but to many I have worked with over the years. I have watched traumatized and broken people of all ages, mend and heal as they have become part of a loving and caring community".

(Cathy page 7)

"Though my motivations for training as a counsellor are multifarious and complex, fundamentally I am driven by a desire for understanding, reconciliation and wholeness in both relationships and community and by the need to love others as an expression of faith. (Ben page 3)

I began to understand that my identity as a religious person assumed care for others, social justice for the oppressed and support for the vulnerable as an outward expression of God's love”. (Ben page 4)

A curiosity and tendency towards an interest in self and other people

"and I recognised that even the basic counselling skills I was learning were so powerful to a human connection that I could build with another person at the end of a telephone. I passed the Drugsline training and started volunteering. I found the work really challenging, often times frustrating but so fulfilling and rewarding. " (Debbie page 8)

“Helping people has always been an important part of me". (Cathy page 1)

"My innately inquisitive nature and desire to further my own learning has led me to consistently embark on a path of personal development". (Cathy page 9)

"how does the therapist become a person capable of offering such a gift which has the power to comfort, to heal, to confer worth, to banish fear, to bring about 
transformation'? My life ambition is to emulate such a person, and I continue on the journey of discovery in order to do so. (Cathy page 10)

"I find this Humanistic view of people, of our natural tendency towards growth and fulfilment of penitential, close to my own beliefs. I find it more inspiring, optimistic and hopeful ... something to inspire (sic) to and work towards" (Emily page 4)

"fundamentally I am driven by a desire for understanding, reconciliation and wholeness in both relationships and community and by the need to love others as an expression of faith." (Ben page 3)

"I am interested in how different arts therapies might enable clients to express their uniqueness through forms of expression of feeling and 'self' that are as just as creative and distinct as the individual themselves". (Ben page 6)

"it was my job to support these young people, from helping them with money, to chatting through issues with them. What I found quite quickly was that I somehow connected with these young people. I found myself getting to know them and building relationships" (Alice page 8)

While expressed differently depending on the research participants' own style and personality, we would suggest each of these excerpts above indicates an orientation towards altruism. A capacity for altruism can be experienced when one feels safe, and when one is emotionally robust and capable of affect regulation (Music, 2011). This then implies a sense of being healed.

One paper in the above review (Guttman and Daniels, 2001) identified narcissistic gains as a motivation, implying a need for self-validation. This was a term used by the researchers not the participants. We agree that we could view these findings through the lens of narcissism, however the students in the present study do not frame it in this way but rather see it as a contribution to society. Narcissism is a term that can be interpreted negatively as self-interest or seen as attempting to fulfil a valid psychological need. The sense of healing implied in the narratives of the present study suggests to us that although there was adversity it had been significantly overcome. There is something redemptive in wanting something better for others and having a genuine desire to nurture others.

The journeys of the research participants from relational adversity through manifestations of their distress to finding some resolution through healing relationships would suggest to us the probability that they have an earned secure attachment style. 


\section{Conclusion}

These essays tell us that these students identify their motivations to study to become therapists as being rooted in their own childhood and adolescent experiences of relational adversity; the subsequent experience of psychological distress and the restorative experience of relationship leading to accessing availability for relationship themselves. They do not tell us explicitly why they have chosen to work with children and young people rather than with adults, but implicitly we can surmise that they hope to alleviate the pain of other young people and that their own experiences furnish them with the relevant understanding.

We recognise these motivations from the often-used metaphor of the wounded healer that is employed to describe therapists. What is important to note here is that these participants also have a sense of their wounds being in the process of being healed. The restorative experiences following the adversity are crucial. So, for these students there is the sense of being 'healed enough' to begin the journey to become therapists. This is not to imply that no further personal development is required. On the contrary, we would suggest that students' awareness of their own personal process develops over the course but the present study highlights the importance of restorative experiences in their backgrounds. The motivation to study identified by these students chimes with what was identified by the literature review despite the literature solely focusing upon adult therapists. The exception is that of the parentified child. The review of the literature revealed one motivation to stem from experiences of being a parentified child. This was not a dominant theme in our study. Could this be a difference between those who work with adults and those who work with children? The parentified child takes care of the adult parent and perhaps goes on to be a therapist for adults. This is perhaps an area for future investigation.

There are implications here for those who are involved in the initial or continuing education of therapists. We suggest that this study highlights the need for practitioner self-awareness so that the feelings of relational adversity are not denied, neglected or split off and therefore be at risk of being projected onto the client. So courses need to offer opportunities for reflection on childhood experiences in psychologically safe settings. It is also another argument for mandatory personal therapy for therapists during their initial education and is therefore of interest to those responsible for accreditation and registration for the profession. There are also implications for those who select and admit people on courses in that these findings need to be kept in mind when considering and judging the suitability of candidates. The sparse literature on this topic and the small scale of this study suggest that further research would be helpful in illuminating further the motivations to choose this profession. 


\section{References}

Barnett, M (2007) What Brings You Here? An exploration of Unconscious Motivations of those who choose to train and work as psychotherapists and counsellors. In Psychodynamic Practice 13 (3), p. 257-274

Burton, M and Topham, D (1997) Early Loss Experiences in Psychotherapists, Church of England Clergy, Patients Assessed for Psychotherapy and Scientists and Engineers. In Psychotherapy Research 7 (3), p.275-300

Clandinin, D.J. (2007) Handbook of Narrative Inquiry. London: Sage

Cooper, M. (2013) School-based Counselling in UK Secondary Schools: A review and Critical Evaluation

DiCaccavo, A (2002) Investigating Individuals' motivations to become counselling psychologists: The influence of early caretaking roles within the family. In Psychology and Psychotherapy: Theory, Research and Practice. 75, p.463-472

DfE, 2015a https://www.gov.uk/government/publications/counselling-in-schools

DfE, 2015b

https://www.gov.uk/government/uploads/system/uploads/attachment_data/file/416786/Mental Health_and_Behaviour___Information_and_Tools_for_Schools_240515.pdf

DfE, 2016a

https://www.gov.uk/government/uploads/system/uploads/attachment_data/file/497825/Couns elling_in_schools.pdf

DfE, 2016b

https://www.gov.uk/government/uploads/system/uploads/attachment_data/file/508847/Mental _Health_and_Behaviour___advice_for_Schools_160316.pdf

Doncaster, K. and Lester, S. (2002) Capability and its Development: experiences from a work based doctorate Studies in Higher Education Volume 27, No. 1, 2002

Fussell, F and Bonney, W (1990) A Comparative Study of Childhood Experiences of Psychotherapists and Physicists: Implications for Clinical Practice. In Psychotherapy. Vol. 27, No. 4

Guttman, J and Daniels, S (2001) What do School Counsellors Gain from their role as Psychotherapists? In Educational Psychology. Vol. 21, No. 2

Hill, C. E., Knox, S., Thompson, B. J., Williams, E. N., Hess, S. A., \& Ladany, N. (2005). 
Consensual qualitative research: An update. Journal of Counseling Psychology, 52(2), 196-205. doi:10.1037/0022-0167.52.2.196

Holliday, C. (2015) What informs our interventions? BACP Children and Young People Journal

O'Brien, M. (2015) The First Step: The Review of Personal and Professional Learning. In: S.

Goss and C. Stevens (Eds) Making Research Matter. London: Routledge.

McLeod, J. (2011) The Counselling Workbook: Developing a Personal Approach (2nd edition). Berkshire: Open University Press.

Murphy, R and Halgin, R (1995) Influences on Career Choice of Psychotherapists. In Professional Psychology: Research and Practice. Vol. 26 No.4, p.422-426

Ponterotto,G. Qualitative Research in Counseling Psychology: A Primer on Research Paradigms and the Philosophy of Science. Journal of Counseling Psychology, 2005, Vol 52, No 2, 126-136

Therapy Today BACP News Vol 25, Issue 10 Dec 2014

http://www.therapytoday.net/article/show/4631/ 